\title{
Effect of Structure of Monocyclic Aromatic Solvents on the Packing Density of Fullerene $\mathrm{C}_{60}$ Solvation Shell
}

\author{
E. V. Chubarova and E. Yu. Melenevskaya \\ Institute of Macromolecular Compounds, Russian Academy of Sciences, Bolshoi Avenue 31, 199004 St. Petersburg, Russia \\ Correspondence should be addressed to E. V. Chubarova, e.v.chubarova@mail.ru
}

Received 30 August 2012; Accepted 12 October 2012

Academic Editors: X. C. Li, U. Pal, Y. Ueno, and M. I. M. Wazeer

Copyright (C 2012 E. V. Chubarova and E. Yu. Melenevskaya. This is an open access article distributed under the Creative Commons Attribution License, which permits unrestricted use, distribution, and reproduction in any medium, provided the original work is properly cited.

\begin{abstract}
Fullerene $\mathrm{C}_{60}$ solutions in various monocyclic aromatic solvents (AS) diluted by tetrahydrofurane (THF) were studied using UV spectroscopy. An algorithm was proposed which made it possible to obtain the data from the UV spectra of $\left(\mathrm{C}_{60}+\mathrm{AS}\right)$ solutions in THF which pointed to the difference between the packing density of AS molecules in solvation shell of $\mathrm{C}_{60}$ and that in the pure AS solvent. The presence of asymmetrical substituents in the AS molecule has been shown to result in loosening of solvent structure in the solvation shell, while the absence of the substituents or presence of symmetrical substituents leads to compacting of solvent structure.
\end{abstract}

\section{Introduction}

Donor-acceptor interactions of fullerene $\mathrm{C}_{60}$ with solvent molecules are responsible for its good solubility in numerous organic solvents due to formation of strong solvation shells [1]. Fullerene $\mathrm{C}_{60}$ manifests itself mainly as a $\pi$-acceptor [1-3], which predominates its high solubility in aromatic solvents due to formation of fullerene-solvent molecular complexes. The presence of substituents in the aromatic solvent (AS) molecule may be expected to result in the appearance of additional interactions between the AS and $\mathrm{C}_{60}$ during solvation. For example, the spectroscopic study of fullerene solutions in various solvents $[4,5]$ pointed to the possibility of $\mathrm{C}_{60}$ solvation by $o$-dichlorobenzene owing to both $\pi-\pi$ interactions of the benzene ring of AS with the $\pi$-system of fullerene and partial charge transfer from the chlorine atom to fullerene. The presence of methyl group as a substituent in the AS molecule may open the way to formation of additional hydrogen-bonding complexes [6]. Interaction of some organic donors with $\mathrm{C}_{60}$ has been shown to result in their coordination with fullerene $C_{60}$ [7]. The structure of solvation shell would be dependent on the forced coordination of solvent molecules by fullerene. The fullerene ability to structure a solvent was shown in [8]. It seems quite obvious that the coordination of monocyclic AS molecules by $\mathrm{C}_{60}$ during solvation would depend on the presence of substituents in AS which may interact with fullerene. The forced coordination of solvent molecules by $\mathrm{C}_{60}$ may be proposed to result in the difference between the packing density of AS molecules in the $\mathrm{C}_{60}$ solvation shell and that in the pure AS. The examination of this idea was the aim of the work.

\section{Experimental Part}

2.1. Materials, Experimental Procedure, and Equipment. Fullerene $\mathrm{C}_{60}$ (purity $99.5 \mathrm{wt} \%$ ) (Fullerene Technologies, St. Petersburg) was used for preparation of its solutions with specified concentrations in several selected aromatic solvents with various substituents (Table 1 ) as well as in tetrahydrofurane (THF) and methylene chloride $\left(\mathrm{CH}_{2} \mathrm{Cl}_{2}\right)$. All solvents were preliminary purified by distillation.

The weighed amount of $\mathrm{C}_{60}$ solution in AS with the known fullerene concentration was diluted by the weighed amount of THF, which allowed us to calculate the concentration of fullerene $\left(c_{F}\right)$ and of the AS used $\left(c_{\mathrm{AS}, \text { cal }}\right)$ in the $\left(\mathrm{C}_{60}+\mathrm{AS}\right)$ solution in THF. No less than three solutions diluted by THF were prepared from the $\mathrm{C}_{60}$ solution in each AS; 
TABLE 1: Aromatic solvents used and the number $N$ of excess (positive values) or deficient (negative values) molecules of the aromatic solvent per solvation shell of $\mathrm{C}_{60}$ molecule.

Solvent

for each $\left(\mathrm{C}_{60}+\mathrm{AS}\right)$ solution in THF the UV spectrum was recorded.

The UV spectra of $\mathrm{C}_{60}$ solutions were recorded using a UV VIS SF-2000 spectrophotometer (Russia); quartz cells of $2 \mathrm{~mm}$ thickness were used.

2.2. The Procedure of Calculation of the Number of Excess or Deficient Molecules of AS per Solvation Shell of $C_{60}$ Molecule. Tetrahydrofurane is a transparent in the UV-region solvent good for AS and poor for $\mathrm{C}_{60}$. At addition of THF to $\mathrm{C}_{60}$ solution in AS, fullerene solvation shell will be defined as the number of AS molecules which $\mathrm{C}_{60}$ is able to retain in THF. If the packing density of AS molecules in solvation shell corresponds to that in the pure AS solvent, the concentration $c_{\mathrm{AS}, \mathrm{sp}}$ calculated from the spectra of the $\left(\mathrm{C}_{60}+\mathrm{AS}\right)$ solution in THF must be equal to the concentration $c_{\mathrm{AS} \text {,cal }}$ calculated for this solution from the weighed amounts of $\mathrm{C}_{60}$ solution in AS and of THF. To calculate $c_{\mathrm{AS} \text {,sp }}$ concentration, it is necessary to isolate the $\mathrm{C}_{60}$ spectrum from the $\left(\mathrm{C}_{60}+\mathrm{AS}\right)$ spectrum in the region of the combined absorbance of AS and $\mathrm{C}_{60}$ (at $\lambda<300 \mathrm{~nm}$ ). The following algorithm was developed to

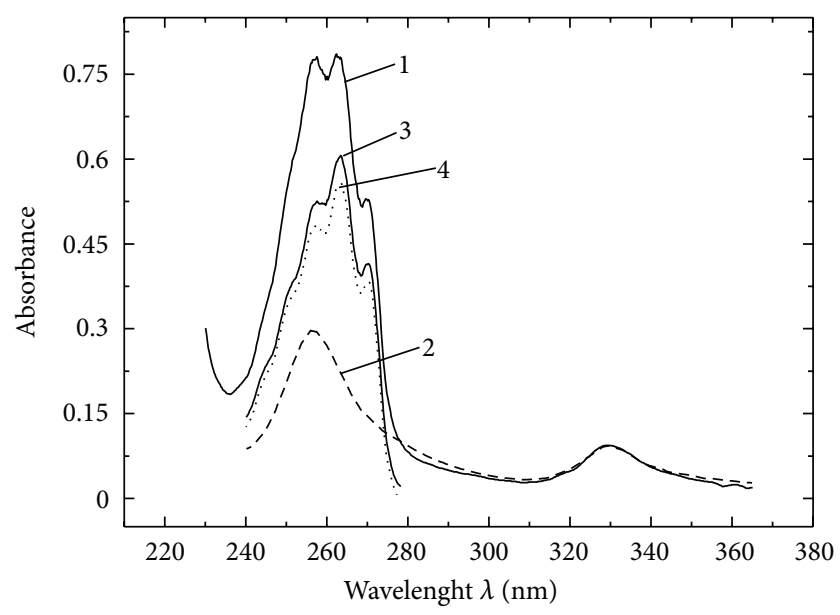

FIGURE 1: Graphic illustration of the procedure of obtaining the AS spectra corresponding to the true value $c_{\mathrm{AS} \text {,sp }}$ of AS concentration from the spectrum of (1) $\left(\mathrm{C}_{60}+\mathrm{AS}\right)$ solution in THF. (2) is the transformed standard spectrum of $\mathrm{C}_{60}$; (3) is the spectrum of AS corresponding to $c_{\mathrm{AS}, \mathrm{cal}} ;(4)$ is the spectrum of AS obtained as the difference (1) and (2) spectra and corresponding to the required concentration $c_{\mathrm{AS}, \mathrm{sp}}$ (AS is chlorobenzene; $c_{F}=0.0058 \mathrm{mg} / \mathrm{mL}$, $c_{\text {chlorbenzene,cal }}=1.974 \mathrm{mg} / \mathrm{mL}$, and $c_{\text {chlorobenzene,sp }}=1.806 \mathrm{mg} / \mathrm{mL}$ ).

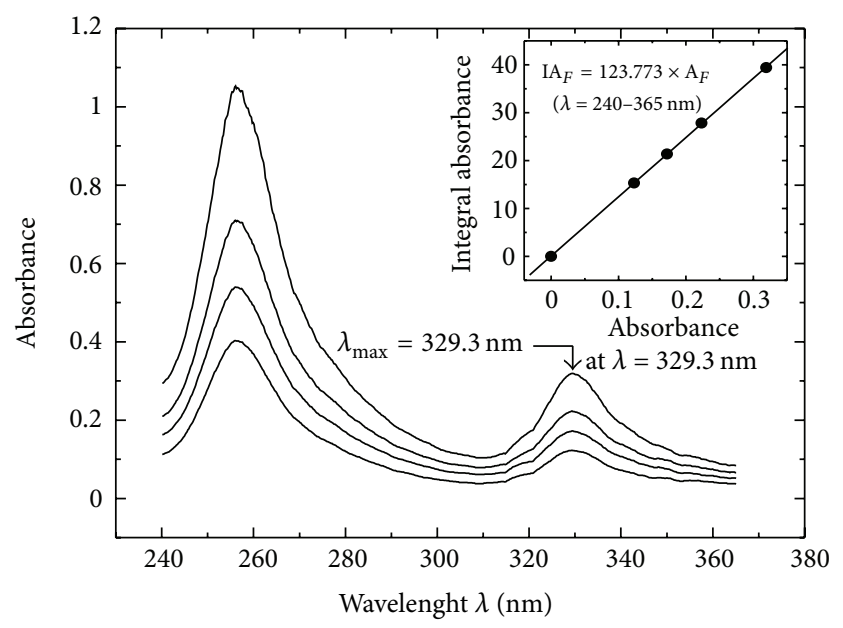

Figure 2: The UV spectra of $\left(\mathrm{C}_{60}+\mathrm{CH}_{2} \mathrm{Cl}_{2}\right)$ solution in THF obtained by serial dilution. The insert shows the calibration dependence of the integral absorbance $\mathrm{IA}_{F}$ of $\left(\mathrm{C}_{60}+\mathrm{CH}_{2} \mathrm{Cl}_{2}\right)$ solution in THF on the absorbance value $A_{F}$ at $\lambda=329.3 \mathrm{~nm}$.

evaluate the $c_{\mathrm{AS} \text {,sp }}$ concentrations of AS from the spectra of $\left(\mathrm{C}_{60}+\mathrm{AS}\right)$ solutions in THF.

The graphic illustration of the algorithm proposed is presented in Figure 1. Curve 1 in Figure 1 corresponds to the spectrum of $\left(\mathrm{C}_{60}+\mathrm{AS}\right)$ solution in THF with known concentration $c_{\mathrm{AS} \text {,cal }}$ and, supposedly, is a superposition of $\mathrm{C}_{60}$ and AS spectra.

To recover the individual $\mathrm{C}_{60}$ spectrum, the following calibration procedure was developed. From the UV spectra recorded for $\mathrm{C}_{60}$ solution in $\mathrm{CH}_{2} \mathrm{Cl}_{2}$ under gradual addition of THF (Figure 2), the linear dependence, $\mathrm{IA}_{F}=C \cdot \mathrm{A}_{F}$, of the integral absorbance $\mathrm{IA}_{F}$ of $\mathrm{C}_{60}$ (the area under every 


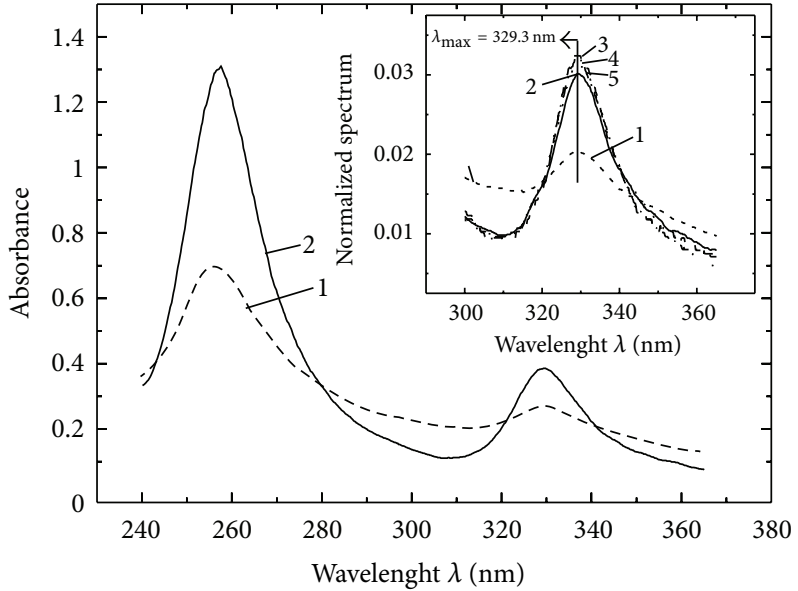

Figure 3: The UV spectra of $\mathrm{C}_{60}$ (1) in THF and (2) in $\mathrm{CH}_{2} \mathrm{Cl}_{2}$. The insert shows the normalized UV spectra of (1) $\mathrm{C}_{60}$ in THF, (2) $\left(\mathrm{C}_{60}+\mathrm{CH}_{2} \mathrm{Cl}_{2}\right)$ in THF, and $\left(\mathrm{C}_{60}+\mathrm{AS}\right)$ solutions in THF in the region transparent for $\mathrm{C}_{60}$ : (3) AS is toluene, (4) AS is p-xylene, and (5) AS is chlorobenzene.

individual spectral curve) in the wavelength range $\lambda=240-$ $365 \mathrm{~nm}$ on the absorbance $\mathrm{A}_{F}$ of $\mathrm{C}_{60}$ at $\lambda_{\max }=329.3 \mathrm{~nm}$ was obtained (the insert in Figure 2).

The spectrum of $\left(\mathrm{C}_{60}+\mathrm{CH}_{2} \mathrm{Cl}_{2}\right)$ solution in THF was taken in the calculations for the standard spectrum of $\mathrm{C}_{60}$, since $\left(\mathrm{C}_{60}+\mathrm{CH}_{2} \mathrm{Cl}_{2}\right)$ is transparent at $\lambda>230 \mathrm{~nm}$ (curve 2 in Figure 3), and fullerene does not aggregate in $\mathrm{CH}_{2} \mathrm{Cl}_{2}$ in contrast to $\mathrm{C}_{60}$ in THF (curve 1 in Figure 3 ) $[1,5]$. Besides, the position of the absorption maximum $\left(\lambda_{\max }=329.3 \mathrm{~nm}\right)$ of $\mathrm{C}_{60}$ band and the width of this band for $\left(\mathrm{C}_{60}+\mathrm{CH}_{2} \mathrm{Cl}_{2}\right)$ solution in THF coincides with that of the visible $\mathrm{C}_{60}$ band for all $\left(\mathrm{C}_{60}+\mathrm{AS}\right)$ solutions in THF (the insert in Figure 3).

Curve 2 in Figure 1 corresponds to the $\mathrm{C}_{60}$ spectrum obtained by transformation of the spectrum of $\left(\mathrm{C}_{60}+\right.$ $\mathrm{CH}_{2} \mathrm{Cl}_{2}$ ) solution in THF with the known value of integral absorbance (for any spectral curve in Figure 2). The transformation of the selected standard $\mathrm{C}_{60}$ spectrum with the known $\mathrm{IA}_{F}$ value to the $\mathrm{C}_{60}$ spectrum corresponding to the absorbance value at $\lambda_{\max }=329.3 \mathrm{~nm}$ in the $\left(\mathrm{C}_{60}+\mathrm{AS}\right)$ spectrum was carried out by multiplication of absorbance values of the standard $\mathrm{C}_{60}$ spectrum by the ratio of integral absorbance calculated from the calibration dependence $\mathrm{IA}_{F}=C \cdot \mathrm{A}_{F}$ to the integral absorbance of the standard spectrum.

From the UV spectra of AS solutions in THF recorded at specified concentrations $c_{\mathrm{AS}}$ of AS (Figure 4) the linear calibration dependences $\mathrm{IA}_{\mathrm{AS}}=B_{\mathrm{AS}} \cdot c_{\mathrm{AS}}$ (the insert in Figure 4) were obtained for all aromatic solvents used, where $\mathrm{IA}_{\mathrm{AS}}$ is the integral absorbance (the area under the spectral curve of AS at $c_{\mathrm{AS}}$ ) within the absorption range of AS (from $\lambda_{1}$ to $\lambda_{2}$, Figure 4 ).

Using the calibration $\mathrm{IA}_{\mathrm{AS}}=B_{\mathrm{AS}} \cdot c_{\mathrm{AS}}$, the standard spectrum of AS (the spectrum with a known value of $\mathrm{IA}_{\mathrm{AS}}$ ) in THF was transformed to the AS spectrum corresponding to the respective concentration $c_{\mathrm{AS} \text {, cal }}$ of AS in the $\left(\mathrm{C}_{60}+\mathrm{AS}\right)$ solution in THF (curve 3 in Figure 1). The spectrum (curve 4

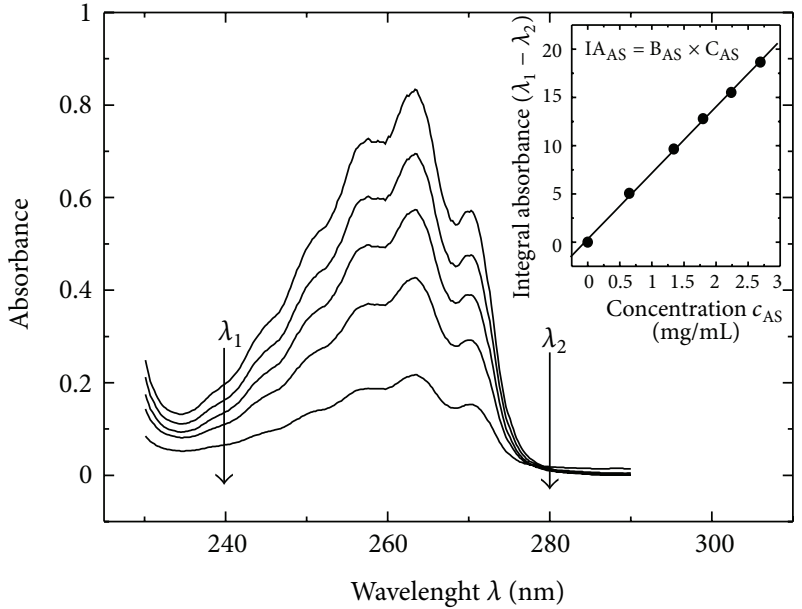

FIgURE 4: The UV spectra of AS solution in THF obtained at different concentrations of AS (AS is chlorbenzene; the UV spectra were obtained at $c_{\text {chlorobenzene }}=0.648,1.342,1.799,2.239$, and $2.692 \mathrm{mg} / \mathrm{mL}$ ). The insert shows the calibration dependence of the integral absorbance $\mathrm{IA}_{\mathrm{AS}}$ of AS solution in THF on AS concentration (AS is chlorobenzene; $\mathrm{IA}_{\text {chlorobenzene }}=6.853 \cdot c_{\text {chlorbenzene }}$; the $\lambda$ range is $240-280 \mathrm{~nm}$ ).

in Figure 1) obtained by subtraction of the absorbance values of $\mathrm{C}_{60}$ (curve 2) from the absorbance values of $\left(\mathrm{C}_{60}+\mathrm{AS}\right.$ ) (curve 1) is the spectrum of AS which corresponds to the true concentration $c_{\mathrm{AS}, \mathrm{sp}}$ of AS in solution. The integral absorbance $\mathrm{IA}_{\mathrm{AS}, \mathrm{sp}}$ of AS was obtained as the difference between the integral absorbance of $\left(\mathrm{C}_{60}+\mathrm{AS}\right)$ solution and the calculated integral absorbance $\mathrm{IA}_{F}$ of $\mathrm{C}_{60}$. The concentration $c_{\mathrm{AS}, \mathrm{sp}}$ of AS was calculated from the value of $\mathrm{IA}_{\mathrm{AS}, \mathrm{sp}}$, obtained from the calibration $\mathrm{IA}_{\mathrm{AS}}=B_{\mathrm{AS}} \cdot c_{\mathrm{AS}}$.

In accordance with the $c_{\mathrm{AS}, \mathrm{cal}}$ and $c_{\mathrm{AS}, \mathrm{sp}}$ values obtained for each $\left(\mathrm{C}_{60}+\mathrm{AS}\right)$ solution in THF, the number $N$ of excess (positive values) or deficient (negative values) molecules of AS per solvation shell of $\mathrm{C}_{60}$ molecule was calculated from the relation

$$
N=\frac{\Delta c_{\mathrm{AS}}}{c_{F}} \frac{M_{F}}{M_{\mathrm{AS}}}
$$

where $\Delta c_{\mathrm{AS}}=\left(c_{\mathrm{AS}, \mathrm{sp}}-c_{\mathrm{AS}, \mathrm{cal}}\right), M_{F}$, and $M_{\mathrm{AS}}$ are the molecular masses of $\mathrm{C}_{60}$ and $\mathrm{AS}$, respectively.

\section{Results and Discussion}

For all $\left(\mathrm{C}_{60}+\mathrm{AS}\right)$ solutions in THF the AS concentration $c_{\mathrm{AS} \text {,sp }}$ obtained with the proposed algorithm differed from the $c_{\mathrm{AS} \text {, cal }}$ value. Thus, the comparison of the chlorbenzene spectrum corresponding to the calculated concentration $c_{\text {chlorobenzene,cal }}$ in THF (curve 3 in Figure 5) with the spectrum corresponding to the true concentration of chlorobenzene (curve 4 in Figure 5) shows that the true concentration is lower than the calculated one.

The comparison of the spectrum corresponding to the calculated $p$-xylene concentration $c_{p \text {-xylene,cal }}$ (curve 3 in Figure 6) with the spectrum corresponding to the true concentration of $p$-xylene (curve 4 in Figure 6 ) shows that 


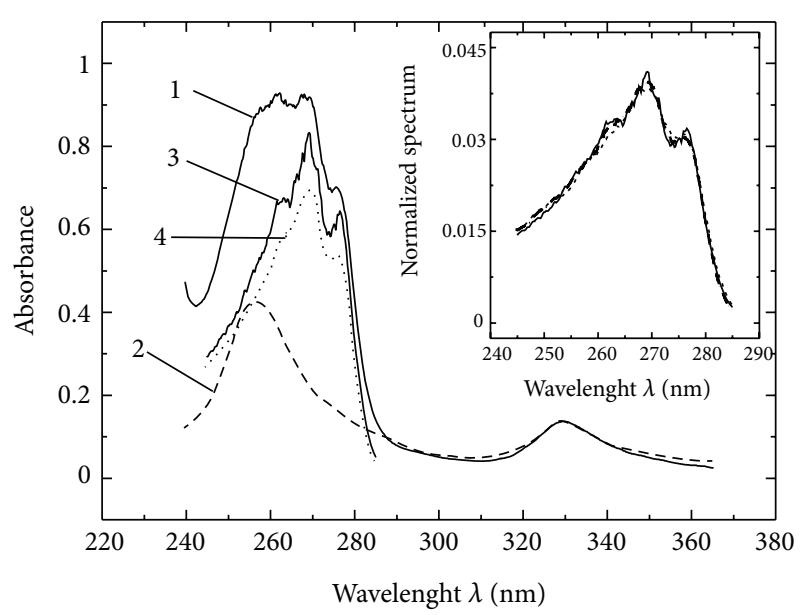

Figure 5: The UV spectra of (1) ( $\mathrm{C}_{60}+o$-dichlorobenzene) solu-

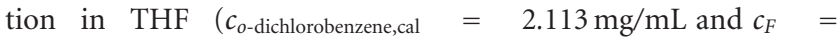
$0.0095 \mathrm{mg} / \mathrm{mL}$ ), (2) the transformed standard spectrum of $\mathrm{C}_{60}$, (3) $o$-dichlorobenzene corresponding to $c_{o \text {-dichlorobenzene,cal }}=$ $2.113 \mathrm{mg} / \mathrm{mL}\left(\mathrm{IA}_{o \text {-dichlorobenzene }}=9.598 \cdot \mathcal{c}_{o \text {-dichlorobenzene }}\right.$ in the $\lambda$ range from 245 to $285 \mathrm{~nm}$ ), and (4) $o$-dichlorobenzene obtained as a difference of (1) and (2) spectra (the calculated value $c_{o \text {-dichlorobenzene,sp }}$ for the spectrum (4) is $1.851 \mathrm{mg} / \mathrm{mL})$. The insert shows the normalized spectrum of $o$-dichlorobenzene in THF (solid line) and the normalized spectra of $o$-dichlorobenzene obtained by subtraction of the $\mathrm{C}_{60}$ spectrum from the spectra of $\left(\mathrm{C}_{60}+o\right.$-dichlorobenzene $)$ solutions in THF with various concentrations of $o$-dichlorobenzene and $\mathrm{C}_{60}: c_{o \text {-dichlorobenzene,cal }}=2.113 \mathrm{mg} / \mathrm{mL}, c_{F}=0.0095 \mathrm{mg} / \mathrm{mL}$ (dash line); $c_{o \text {-dichlorobenzene,cal }}=2.190 \mathrm{mg} / \mathrm{mL}, c_{F}=0.0069 \mathrm{mg} / \mathrm{mL}$

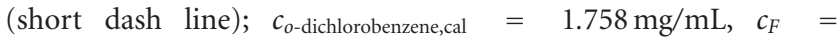
$0.0081 \mathrm{mg} / \mathrm{mL}$ (dot line).

the true concentration exceeds considerably the calculated concentration.

The difference between the $c_{\mathrm{AS}, \text { cal }}$ and $c_{\mathrm{AS}, \mathrm{sp}}$ values found for each $\left(\mathrm{C}_{60}+\mathrm{AS}\right)$ solution in THF points to the change of solvation shell density with respect to the density of pure solvent. The calculated $N$ values are given in Table 1. The data show that the presence of asymmetrical substituents (chlorine atoms or the methyl group) in the AS molecule results in the loosening of solvent structure in the solvation shell of $\mathrm{C}_{60}$, while the absence of substituents (benzene) or the presence of symmetrical substituents ( $p$-xylene) leads to compacting of solvent structure in the $\mathrm{C}_{60}$ solvation shell. The insignificant spread in the calculated $N$ values (below 10\%) supports the validity of the proposed algorithm for calculation of the true AS concentration from the UV spectroscopic data. The validity of the proposed algorithm is supported as well by the practical identity of the normalized real spectra of AS in THF and of the AS spectra obtained as a difference of spectra of $\left(\mathrm{C}_{60}+\mathrm{AS}\right)$ and $\mathrm{C}_{60}$ (see inserts in Figures 5 and 6). The concentration dependences of the integral absorbance of $\mathrm{C}_{60}$ in various aromatic solvents (Figure 7) correlate with the data listed in Table 1. Absorption decreases with the increase of packing density of solvent molecules in the solvation shell of $\mathrm{C}_{60}$.

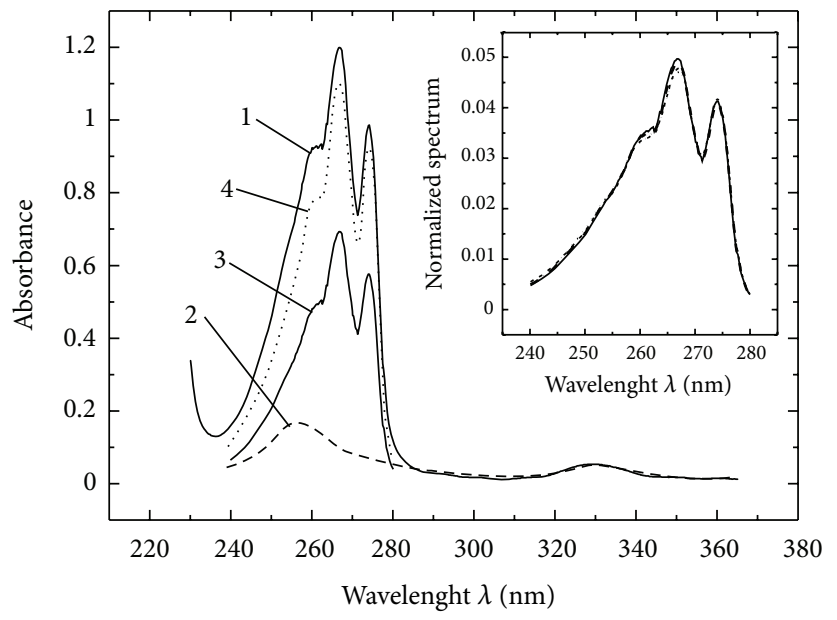

Figure 6: The UV spectra of (1) $\left(\mathrm{C}_{60}+p\right.$-xylene) solution in THF $\left(c_{p \text {-xylene,cal }}=1.548 \mathrm{mg} / \mathrm{mL}\right.$ and $\left.c_{F}=0.0061 \mathrm{mg} / \mathrm{mL}\right),(2)$ the transformed standard spectrum of $\mathrm{C}_{60}$, (3) p-xylene in THF corresponding to $c_{p \text {-xylene }}=1.548 \mathrm{mg} / \mathrm{mL}\left(\mathrm{IA}_{p \text {-xylene }}=9.013 \cdot c_{p \text {-xylene }}\right.$ in the $\lambda$ range from 240 to $280 \mathrm{~nm}$ ), and (4) p-xylene obtained as a difference of (1) and (2) spectra (with the calculated value of $c_{p \text {-xylene,sp }}=2.495 \mathrm{mg} / \mathrm{mL}$ ). The insert shows the normalized spectrum of $p$-xylene in THF (solid line) and normalized spectra of $p$-xylene obtained by subtraction of the $\mathrm{C}_{60}$ spectrum from the spectra of $\left(\mathrm{C}_{60}+p\right.$-xylene $)$ solutions in THF with various concentrations of $p$-xylene and $\mathrm{C}_{60}: c_{p \text {-xylene,cal }}=1.548 \mathrm{mg} / \mathrm{mL}$, $c_{F}=0.0061 \mathrm{mg} / \mathrm{mL}$ (dash line); $c_{p \text {-xylene,cal }}=1.166 \mathrm{mg} / \mathrm{mL}, c_{F}=$ $0.0063 \mathrm{mg} / \mathrm{mL}$ (short dash line); $c_{p \text {-xylene,cal }}=1.378 \mathrm{mg} / \mathrm{mL}, c_{F}=$ $0.0070 \mathrm{mg} / \mathrm{mL}$ (dot line).

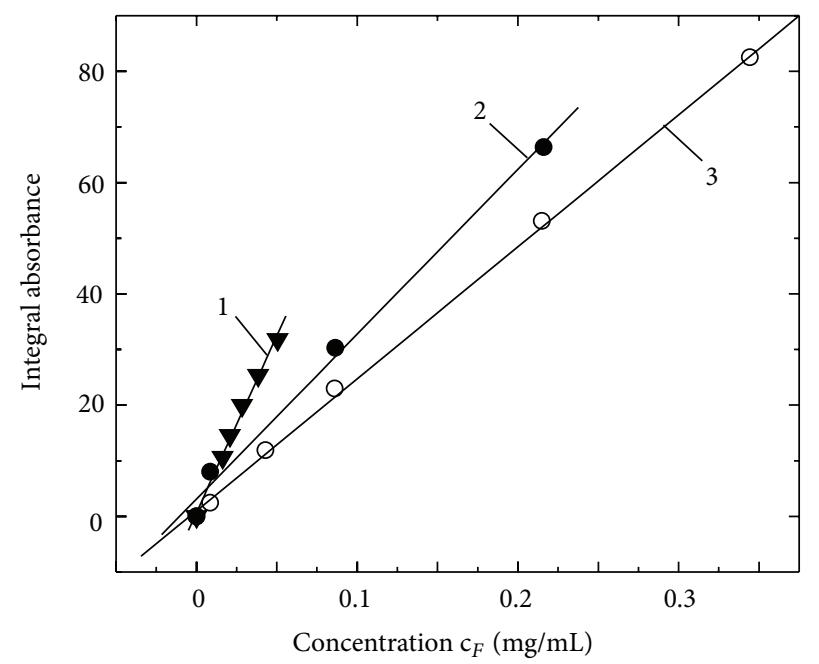

Figure 7: Concentration dependences of the integral absorbance (in the $\lambda$ range from 300 to $365.1 \mathrm{~nm}$ ) of $\mathrm{C}_{60}$ in (1) $o$-xylene, (2) toluene, and (3) p-xylene.

\section{Conclusions}

The idea has been examined that the forced coordination of monocyclic molecules with various substituents of aromatic solvents by fullerene $\mathrm{C}_{60}$ may result in the difference between 
the packing density of AS molecules in the $\mathrm{C}_{60}$ solvation shell and that in the pure AS. In this work, the fullerene solvation shell was defined as the number of AS molecules which the molecule of fullerene is able to retain at addition of THF which is a good solvent for AS and poor for $\mathrm{C}_{60}$, to $\mathrm{C}_{60}$ solution in AS. The analytical techniques applied for preparation of $\mathrm{C}_{60}$ solutions in aromatic solvents and for determination of accurate concentrations $c_{F}$ and $c_{\mathrm{AS} \text {,cal }}$ after addition of THF, as well as the developed calibration procedures, made it possible to obtain the data from the UV spectra of $\left(\mathrm{C}_{60}+\mathrm{AS}\right)$ solutions in THF which is the supporting evidence of the difference between the packing density of AS molecules in the solvation shell of $\mathrm{C}_{60}$ and that in the pure AS solvent. The data obtained show that the presence of asymmetrical substituents (chlorine atoms or methyl group) in the AS molecule results in the loosening of solvent structure in the solvation shell of $\mathrm{C}_{60}$, while the absence of substituents (benzene) or the presence of symmetrical substituents ( $p$-xylene) leads to compacting of solvent structure in the $\mathrm{C}_{60}$ solvation shell.

\section{References}

[1] V. N. Bezmel'nitsyn, A. V. Eletskii, and M. V. Okun', "Fullerenes in solutions," Physics-Uspekhi, vol. 41, no. 11, pp. 1091-1114, 1998.

[2] D. V. Konarev and R. N. Lyubovskaya, "Donor-acceptor complexes and radical ionic salts based on fullerenes," Russian Chemical Reviews, vol. 68, no. 1, pp. 19-38, 1999.

[3] H. Imahori, "Creation of fullerene-based artificial photosynthetic systems," Bulletin of the Chemical Society of Japan, vol. 80, no. 4, pp. 621-636, 2007.

[4] E. V. Chubarova and E. Yu. Melenevskaya, "Analysis of interactions in fullerene-solvent-polymer system by UV-spectroscopy," Fullerenes Nanotubes and Carbon Nanostructures, vol. 16, no. 56, pp. 640-643, 2008.

[5] E. V. Chubarova and E. Yu. Melenevskaya, "Chain degradation during dissolution of polymer-fullerene nanocomposites as a result of interaction of entangled polymer matrix with the filler," Journal of Macromolecular Science B, vol. 49, no. 1, pp. 174206, 2010.

[6] J. Catalán, "On the solvatochromism of $\mathrm{C}_{60}$ and its color in solutions," New Journal of Chemistry, vol. 19, no. 12, pp. 12331242, 1995.

[7] D. V. Konarev, V. N. Semkin, R. N. Lyubovskaya, and A. Graja, "Electronic absorption spectra of the $\mathrm{C}_{60}$ complexes with some organic donors," Synthetic Metals, vol. 88, no. 3, pp. 225-230, 1997.

[8] B. M. Ginzburg, S. Tuichiev, S. K. Tabarov, and A. A. Shepelevskii, "Structurization of a solvent interacting with fullerene C 60 ," Crystallography Reports, vol. 50, no. 5, pp. 735-738, 2005. 


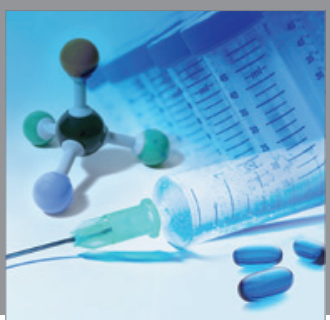

International Journal of

Medicinal Chemistry

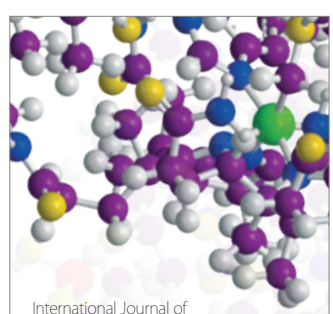

Carbohydrate Chemistry

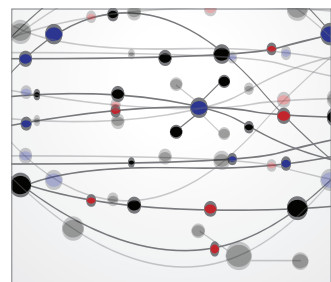

The Scientific World Journal
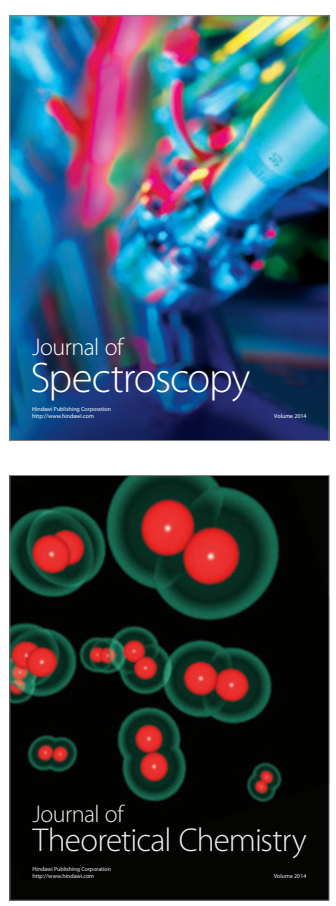
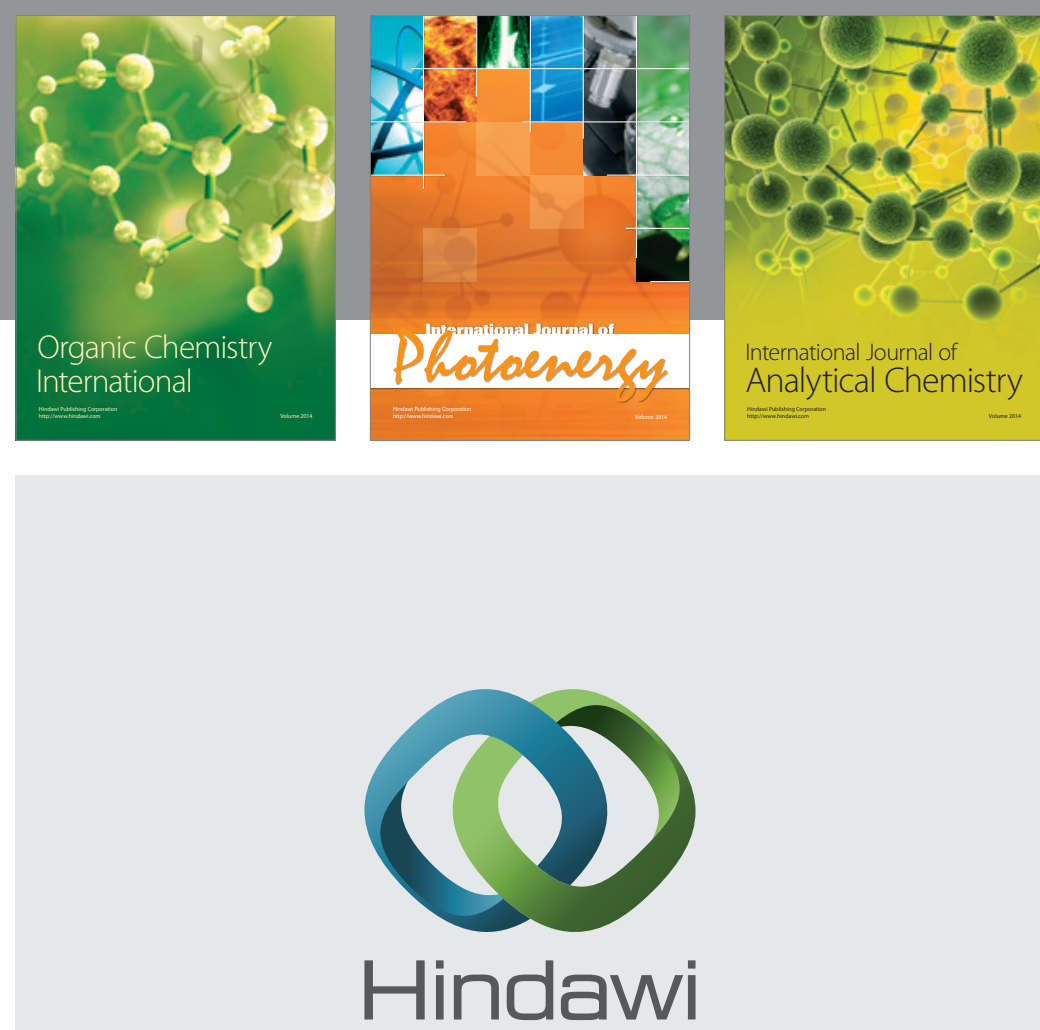

Submit your manuscripts at

http://www.hindawi.com
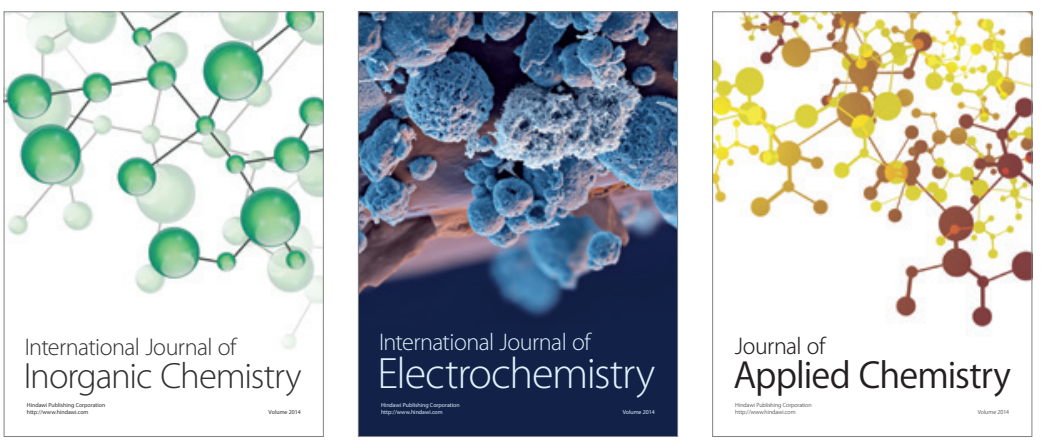

Journal of

Applied Chemistry
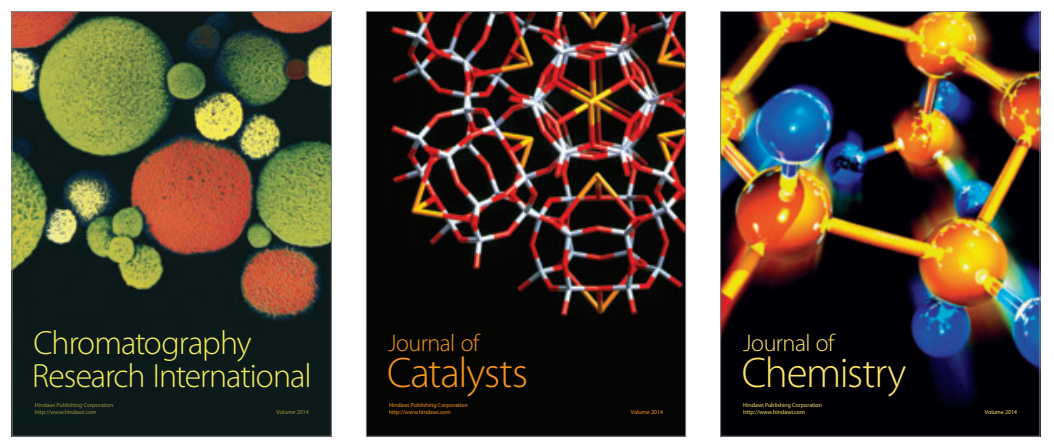
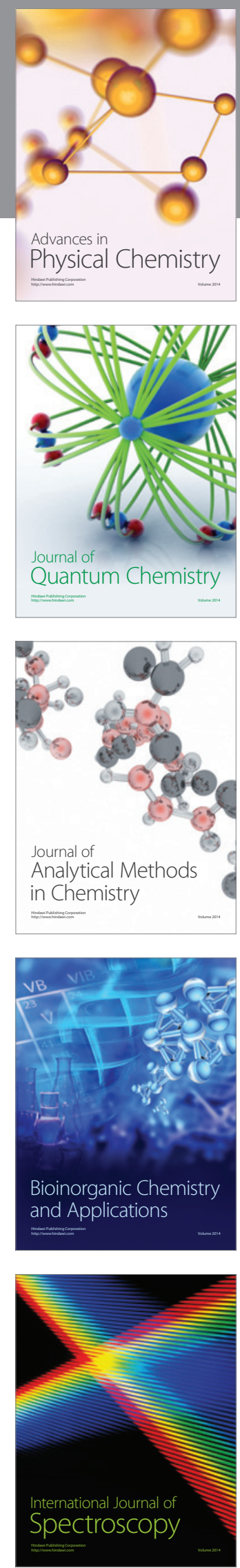